\title{
Portal and Arterial Flushing with HTK and Tacrolimus Can Attenuate the Incidence of Early Liver Allograft Dysfunction
}

\author{
Aliaksei Shcherba, Sergey Korotkov, Denis Efimov, Andrei Minou, Olha Lebedz, Alla Karytka, \\ Dzmitry Fedaruk, Eugeny Santotsky, Aleksandr Dzyadzko, Oleh Rummo
}

Belarusian Republic Center for Organ and Tissue Transplantation,

The $9^{\text {th }}$ Minsk Clinical Hospital, Minsk, Belarus

\section{ABSTRACT}

It was shown that Tacrolimus (TAC) can suppress inflammation and immune response involved in liver ischemic reperfusion injury (IRI) (Kristo I., Transpl Int. 2011).

The aim: We hypothesize that back-table arterial and portal liver perfusion with TAC can influence the incidence and severity of EAD. A prospective randomized study was conducted (ClinicalTrials.gov Identifier: NCT01887171).

Materials and methods: Including criteria: $1^{\text {st }}$ liver transplantation from DBD donor with sequential portal-arterial reperfusion. At back-table portal vein and hepatic artery were perfused each by $500 \mathrm{ml}$ of HTK solution containing $20 \mathrm{ng} / \mathrm{ml}$ TAC during 10-15 min followed by portal flushing with $200 \mathrm{ml} 5 \%$ solution of Albumin containing $20 \mathrm{ng} / \mathrm{ml} \mathrm{TAC}$ and by resting of liver in effluent. No Tac was added in the control group. Primary Outcome: EAD (Olthoff KM, et al. Liver Transpl. 2010) and severe EAD (P.R. Salvalaggio, et al. Transpl. Proceedings, 2012).

Results: No difference was found between groups (main vs. control) in terms of MELD (16 vs. 16 ), steatosis (10 vs. $10 \%$ ), ballooning (45 vs. $40 \%$ ) of liver grafts, recipient's age (50 vs. $50 \mathrm{y}$ ), warm ischemia time (50 vs. $50 \mathrm{~min}$ ) and total ischemia time (482.5 vs. $485.0 \mathrm{~min}$ ). Median donor age was higher in the main group (44.5 vs. $39.0 \mathrm{y})$. The overall rate of EAD was $27.9 \%$. EAD rate was significantly lower in the main group (6/43 vs. $18 / 43 ; p=0.003)$. The rate of moderate-to-severe EAD was lower in the main group (1/43 vs. 10/43; $p=0.009$ ). The median level of AST and ALT $24 \mathrm{~h}$ after reperfusion were significantly lower in the intervention group (1004 vs. $1596 ; p=0.03$ and 449 vs. $759 ; p=0.057$ ).

Conclusion: Portal and arterial back-table liver perfusion by HTK solution with Tacrolimus may contribute to lower EAD incidence and severity.

Key words: liver transplantation, early allograft dysfunction, tacrolimus, immunosupression, arterial and portal flushing

\section{INTRODUCTION}

Liver transplantation (LT) has dramatically changed the prognosis for patients with end-stage chronic liver diseases and certain neoplasms. Success of the

\author{
Corresponding author: \\ Aliaksei Shcherba, PhD \\ Chief of Division of Liver transplantation \\ and Hepatobiliary and pancreatic surgery \\ Minsk Organ \& Tissue Transplant Center \\ Minsk, 220116, Semashko 8, Belarus \\ E-mail: aleina@tut.by
}

Received: 07.05.2016 Accepted: 10.06.2016

Copyright () Celsius Publishing House 
surgery, however, is still complicated by the gap between the number of patients on waiting lists and available donors despite the introduction of SPLIT liver transplantation and live donor transplantation. This gap leads to $10-20 \%$ mortality on waiting lists and the need for use of extended criteria donor (ECD) organs. However, the use of extended criteria donors is associated with early allograft dysfunction (EAD) caused by ischemia reperfusion injury (IRI) (1).

Salvalaggio et al. demonstrated that severe EAD is accompanied with significantly lower one-year survival rate of both the graft $(54.6 \%$ vs. $91.8 \%, p<0.001)$ and the patient $(71.7 \%$ vs. $94 \%, p<0.001)$ as compared to moderate EAD (2). A number of phenotypic risk factors are associated with EAD incidence. Among them: donor older age, serum Sodium level, hepatic steatosis, hypotension, prolonged cold and warm ischemia time, mechanical ventilation $>5$ days, deceased cardiac donor and split or reduced graft (3). MELD score and urgency of transplantation - are well-known recipient's risk factors (4).

As far as most EAD risk factors are impossible (donor age, MELD, urgency, hepatic steatosis, need for vasopressors) or difficult to influence on (cold and warm ischemic time, damage during conditioning), and taking in consideration that cold storage is currently a part of the clinical routine in LT, reduction of total and warm ischemia time and pharmacological liver protection remain the basic strategies of EAD prevention. Due to its availability and reproducibility, pharmacological liver protection is one of the most studied practices of IRI attenuation and EAD prevention. The most available points of administration of pharmacological liver protection are donor conditioning and procurement, back-table flushing and rinse. In this regard, the effects of methylprednisolone (6), sevoflurane (7), nitrogen oxide (8), acetylcysteine, specific P-selectin blocker, etc. were studied (9).

Experimental data point to a possible role of calcineurin inhibitor Tacrolimus in IRI attenuation and liver protection during $\mathrm{LT}(10,11,12)$. Tacrolimus was shown to be able to inhibit inflammation and immune response in the transplanted liver at the genomic level; the available data on protective function of calcineurin inhibitors in cardiac IRI indicate organ-nonspecific possible mechanism of action $(13,14)$. However, clinical efficacy of Tacrolimus for the liver protection remains doubtful due to insufficient power of known studies, patient characteristics and mode of drug administration (13 and 10 patients in a group, mean level of hepatosis $1 \%$, relatively short median total ischemic time, administration only in portal vein or portal and arterial flushing at the time of caval anastomosis formation, i.e. in situ) (15).

In that context we designed a clinical study and hypothesized that back-table portal and arterial liver graft flushing with histidine-tryptophan-ketoglutarate (HTK) solution containing tacrolimus and subsequent portal rinse of donor liver with albumin solution containing tacrolimus, that makes a relatively prolonged exposure of tacrolimus, can reduce the incidence and/or severity of EAD.

\section{AIM}

To investigate whether back-table portal and arterial flushing with HTK and rinse with albumin solution both containing tacrolimus can influence the incidence and severity of EAD.

Primary end-points: incidence and severity of EAD.

Secondary end-points: aspartate aminotransferase (AST) and alanine aminotransferase (ALT) levels during the first 24 and 48 hours after LT, severity of IRI according to liver biopsy 2 hours after portal reperfusion, markers of inflammatory response tested in blood samples of hepatic veins after reperfusion.

\section{MATERIALS AND METHODS}

A prospective randomized single-center doubleblind study was conducted (Evaluation of Preimplantation Portal Vein and Hepatic Artery Flushing with Tacrolimus; registered with clinicaltrials.gov, NCT01887171). Inclusion criteria: donor age $15-65$ years, macrovesicular steatosis $<40 \%$, serum sodium $<165 \mathrm{mmol} / \mathrm{L}$, mechanical ventillation < 11 days, cold ischemia time $<13$ hours, AST and ALT $<200 \mathrm{IU} / \mathrm{L}$, total bilirubin $<30 \mu \mathrm{mol} / \mathrm{L}$; from the recipient's side: age 18 -69 years; transplantation technique with resection of the inferior vena cava, sequential portal and arterial reperfusion and no bypass. Exclusion criteria: LT from a living-related donor, reduced/split graft, LT for fulminant liver failure and re-LT for primary non-function. Calculation of the group size was performed considering the power of the study 0.80 , type I error probability $\alpha=0.05$ and analysis of results of 166 LTs performed before the study. Assuming that utilization of portal and arterial perfusion of liver graft with HTK solution containing tacrolimus causes reduction of EAD incidence from $30 \%$ to $5 \%$, each study group should include 35-41 patients (16). On the grounds of power calculation, 86 patients were included into the study (43 per each group). Randomization was achieved by opening the envelopes before the back-table. 
All deceased donors were administered methylprednisolone in the dose of $1.0 \mathrm{~g}$ intravenously before the beginning of multiple organ retrieval. At the stage of donor operation liver biopsy was performed for subsequent assessment of the severity of hepatic steatosis and balloon dystrophy.

During the back-table the portal vein and common hepatic artery were cannulated. Portal vein flushing was performed under the gravity pressure of $40-60$ $\mathrm{cm}$ with $500 \mathrm{ml}$ of HTK solution containing $20 \mathrm{ng} / \mathrm{mL}$ of tacrolimus. After that hepatic artery flushing was performed with $500 \mathrm{ml}$ of the same solution under the pressure of $40-50 \mathrm{~mm} \mathrm{Hg}$. Then portal rinse was achieved with $200 \mathrm{~mL}$ of $5 \%$ Albumin solution containing $20 \mathrm{ng} / \mathrm{mL}$ of tacrolimus. Donor liver was left in the basin and, in case the expected time to implantation exceeded $30 \mathrm{~min}$, was cooled to $2-6^{\circ} \mathrm{C}$ after packing into sterile plastic bags. In the control group, no tacrolimus was added to the HTK solution. After the end of flushing and rinsing procedure, the effluent from the basin of 16 random cases of the main group was sampled for tacrolimus concentration assessment.

Blood samples from hepatic veins at baseline (immediately after portal reperfusion), one hour after the portal reperfusion, peripheral blood samples 24 and 72 hours after the surgery were used for determination of interleukins (ILs) 2, 6, 8, 17, 23 levels by multiplex immunoassay.

Two hours after portal reperfusion, liver biopsy was performed in order to assess IRI severity. The biopsy sample was placed into buffered formalin and shipped into the morphological laboratory. The protocol for blood and biopsy sampling is presented in table 1 .

Multiplex analysis was performed using Luminex 200 based on XMAP technology by Luminex (USA) with the help of magnetic particles "Milliplex Mag" and panels included into commercial test-systems MILLIPLEX (Millipore, USA). Tacrloimus concentration was deter- mined by instrumental method using the Architect i2000SR analyzer.

EAD was defined according to Olthoff KM et. al. criteria: (1) total bilirubin $>170 \mu \mathrm{mol} / \mathrm{L}$ on the $7^{\text {th }}$ postoperative day, or (2) $\mathrm{MHO}>1.6$ on the $7^{\text {th }}$ postoperative day, or (3) aminotransferases level (AST or ALT) $>2000$ $\mathrm{u} / \mathrm{L}$ during the first postoperative week (17). Severe EAD was defined according to Salvalaggio et al. and divided into mild (AST and ALT $<3000 \mathrm{u} / \mathrm{L}$ ) and moderate-to-severe (AST and ALT > $3000 \mathrm{u} / \mathrm{L}, \mathrm{MHO}>1.6$ and total bilirubin $>170 \mu \mathrm{mol} / \mathrm{L})(2)$.

Statistical analysis was performed using STATISTICA 8 package for Windows and SPSS 22 for Macintosh. Mean values are shown as median (25\%-75\%). Literature search was performed in Pubmed (NLM) electronic database using Endnote ${ }^{\circledR}$ Web software package for Macintosh.

This study was conducted in accordance with the protocol and the principles of the Declaration of Helsinki. The protocol was approved by the Institutional Research Board of the center in accordance with local regulations.

Patient characteristics are presented in table 2 . The groups were comparable by MELD score, recipient age, total and warm ischemic time of the, steatosis and balloon dystrophy severity. Donor age was significantly older in the control group which could have been taken into consideration in case of alternative hypothesis disconfirmation. As far as inclusion criteria allowed only mild bilirubin and AST and ALT elevation in donor, no donors with liver dysfunction exceeding these criteria were included to the study.

\section{RESULTS}

\section{Clinical efficacy}

Median EAD incidence amounted to $27.9 \%$ (24/86).

Table1 - Study protocol

\begin{tabular}{|c|c|c|c|c|c|c|}
\hline \multirow{2}{*}{$\begin{array}{l}\text { Liver biopsy during multiple } \\
\text { organ recovery } \\
\text { (donor biopsy sample) }\end{array}$} & \multicolumn{4}{|c|}{ Blood samples during LT } & \multirow{2}{*}{$\begin{array}{l}\text { Liver biopsy } 2 \\
\text { hours after portal } \\
\text { reperfusion }\end{array}$} & \multirow{2}{*}{$\begin{array}{l}\text { Blood samples } \\
24 \text { and } 72 \\
\text { hours after } \\
\text { reperfusion } \\
\end{array}$} \\
\hline & Portal vein & IVC & \multicolumn{2}{|c|}{ Hepatic veins } & & \\
\hline & & & $\begin{array}{l}0 \text { min after } \\
\text { portal reperfusion }\end{array}$ & $\begin{array}{l}1 \text { hour after } \\
\text { portal reperfusion }\end{array}$ & & \\
\hline $\mathrm{IHC}$ staining for $\mathrm{CD} 68$, & $\mathrm{LBP}, \mathrm{IL}-6$ & & $\begin{array}{l}\text { P-selectin, IL }-2,6 \\
\text { TNF- } \alpha, \text { MIP-1 } \alpha\end{array}$ & $8,17,23$ & $\begin{array}{l}\text { IHC staining for CD68, } \\
\text { HMGB1, HIF- } 1 \alpha \\
\text { HMGB1, HIF- } 1 \alpha\end{array}$ & $\begin{array}{l}\text { IL }-2,6,8,17 \\
23, \text { TNF- } \alpha, \text { MIP- } \\
\text { VEGF }\end{array}$ \\
\hline
\end{tabular}

$\mathrm{IHC}=$ immunohistochemical, LBP = lipopolysaccharide-binding protein, IVC = inferior vena cava 
Table 2 - Patient characteristics

\begin{tabular}{|c|c|c|c|c|}
\hline \# & Parameter & $\begin{array}{l}\text { Main group, } \\
n=43\end{array}$ & $\begin{array}{c}\text { Comparison group, } \\
n=43\end{array}$ & p \\
\hline 1 & MELD & $16(11 ; 20)$ & $16(14 ; 21)$ & 0.43 \\
\hline 2 & Recipient age, years & $50(38 ; 56)$ & $50(40 ; 58)$ & 0.54 \\
\hline 3 & Donor age, years & $44.5(37 ; 51)$ & $39(26 ; 47)$ & 0.043 \\
\hline 4 & Total ischemic time, min & $482.5(400 ; 525)$ & $485(425 ; 515)$ & 0.93 \\
\hline 5 & Warm ischemic time, min & $50(45 ; 60)$ & $50(45 ; 60)$ & 0.52 \\
\hline 6 & Hepatic steatosis, \% & $10(3 ; 20)$ & $10(3 ; 30)$ & 0.68 \\
\hline 7 & Balloon dystrophy, \% & $45(30 ; 50)$ & $40(15 ; 55)$ & 0.7 \\
\hline 8 & Blood loss, $\mathrm{mL}$ & $1200(900 ; 1700)$ & $1500(800 ; 2200)$ & 0.33 \\
\hline
\end{tabular}

EAD according to criteria of Olthoff KM et al. developed in 6 patients of the main group (13.9\%), which was significantly less than in the control group, 18/43 $(41.8 \%),\left(\alpha^{2}=6.33 ; p=0.003\right)$. Moderate-to-severe EAD incidence according to criteria of Salvalaggio et al. in the main group, $1 / 43$ (2.3\%) was also significantly less than in the control group, 10/43 (23.2\%), (Fisher exact; $\mathrm{p}=0.009$ ).

The analysis of maximum AST and ALT values during the first 24 and 48 hours after reperfusion demonstrated that the $\mathrm{AST}_{24}$ level in the main group, 1004 (641;1515) u/L, was significantly and reliably lower than that in the control group, $1596(675 ; 2781)$ $\mathrm{u} / \mathrm{L}$ (Mann-Whitney; $\mathrm{p}=0.03$ ). There was a tendency to lower ALT 24 level in the main group, $449(384 ; 939) \mathrm{u} / \mathrm{L}$ as compared to the control group, $759(437 ; 1087) \mathrm{u} / \mathrm{L}$ (Mann-Whitney; $p=0.057$ ). Less significant differences were received for median maximum values, $\mathrm{AST}_{48}$ and $\mathrm{ALT}_{48 .}$ (graphic 1)

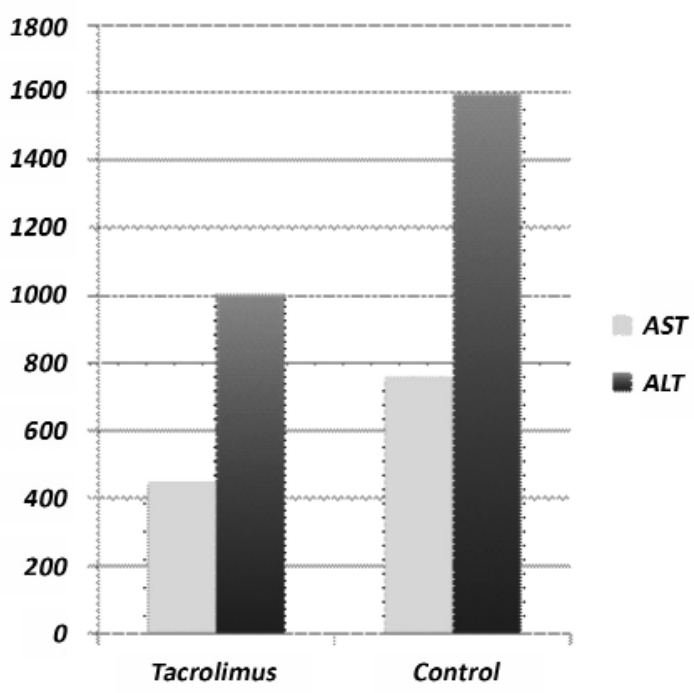

Graphic 1
Primary non-function of the graft developed in one case in each group (Fisher exact; $p=1$ ). Renal failure incidence requiring renal replacement therapy in early postoperative period did not differ in the main, 9/43, and control, $6 / 43$, groups $\left(\chi^{2}=0.7 ; p=0.5\right)$. Septic complications incidence showed no significant differences in the studied groups, as well, and accounted to $20 \%$ $(9 / 43)$ in the main group and $16.2 \%(7 / 43)$ in the control group $\left(\chi^{2}=0.31 ; p=0.7\right)$.

Hospital mortality amounted to $4.6 \%(2 / 43)$ in the main group and was slightly lower than that in the control group 6.9\% (3/43), (Fisher exact; $p=1$ ). The fatal cases on days 28 and 60 in the main group were caused by PNF of the graft in the first case and by sepsis in both cases (MRSA + Acinetobacter and Enterococcus + Acinetobacter). The reason of the fatal cases on days 7 , 23 and 65 in the control group was PNF of the graft $(n=1)$, acute herpetic hepatitis $(n=1)$ and sepsis $(n=1$; Enterococcus + Acinetobacter).

\section{IRI}

Morphological study for IRI evaluation was performed in 23 cases in the control group and in 24 cases in the main group. Severe IRI incidence (necrosis in the pericentral and the $2^{\text {nd }} z o n e>30 \%$, apoptosis $3-5 \%$ ) amounted to $26 \%(6 / 23)$ in the control group and was significantly greater than that in the main group, 4,1\% (1/24), (Fisher exact; $p=0.04$ ). Moderate-to-severe IRI demonstrated statistically less significant difference between the groups (necrosis $>15 \%$, apoptosis $1.5-$ $5 \%$ ).

\section{Tacrolimus effluent concentration}

Median TAC concentration in effluent in which the donor liver was submerged after the end of the perfusion amounted to $6.6(5.3 ; 14.7) \mathrm{ng} / \mathrm{mL}$. 


\section{Serologic markers}

Recent data (4) suggests about involvement of cytokines into the IRI mechanism and considers them as potential surrogate markers of tacrolimus perfusion efficacy/inefficacy.

In our study the difference in the IL-17 level between hepatic vein blood samples measured immediately after portal reperfusion and one hour after it was significantly less in the group of patients receiving arterial-portal flushing with tacrolimus and portal rinse during the back-table (fig. 1).

In the tacrolimus group a statistically significant reduction of the IL- 6 concentration 24 hours after the surgery was noted, $2.2(0.1 ; 20.9) \mathrm{ng} / \mathrm{mL}$, as compared to

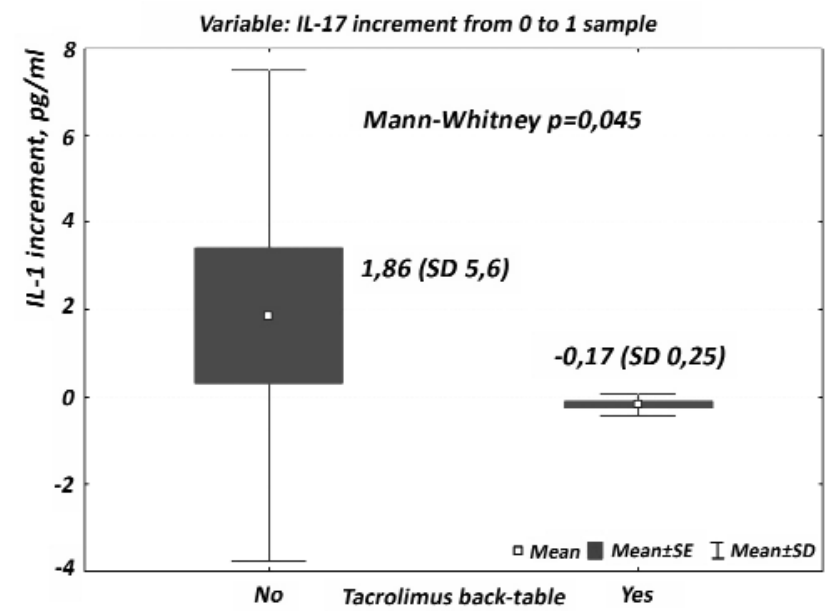

Figure 1 - Increase of IL-17 levels in the hepatic vein blood samples between groups with and without tacrolimus infusion into the portal vein and hepatic artery during "back table"

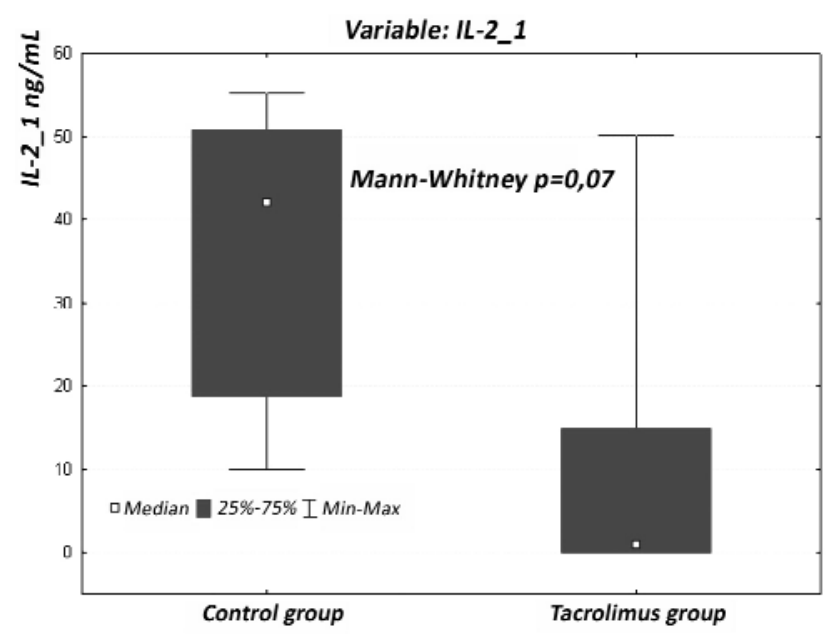

Figure 3 - Differences in IL-2 concentration 24 hours after surgery in the blood samples between control and tacrolimus groups the control group, 37.6 (6.1;56.2) ng/mL, $\mathrm{p}=0.03$; (fig. 2) and the tendency to reduction of the IL-2 concentration 24 hours after the surgery, $0.83(0.1 ; 14.9) \mathrm{ng} / \mathrm{mL}$, as compared to the IL-2 level, $42.01(18.9 ; 50.6) \mathrm{ng} / \mathrm{mL}$, in the group without tacrolimus ( $\mathrm{p}=0.07 ;$ fig. 3 ). Also, $a$ trend toward reduction of the IL-23 level was noted in the hepatic veins sample 1 hour after reperfusion in the main group as compared to the IL-23 level in the group without tacrolimus ( $p=0.05 ;$ fig. 4).

\section{DISCUSSION}

Pharmacological liver protection is theoretically justified by necessity to attenuate IRI as the cause of EAD in LT. Bussutil et al. suggested IRI mechanism with

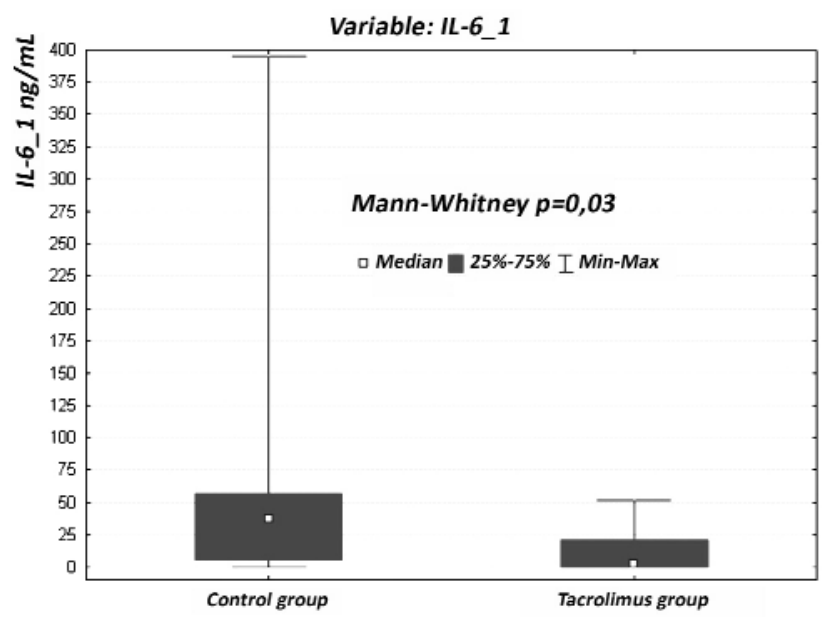

Figure 2. Differences in IL-6 concentration 24 hours after surgeryin the blood samples between control and tacrolimusgroups

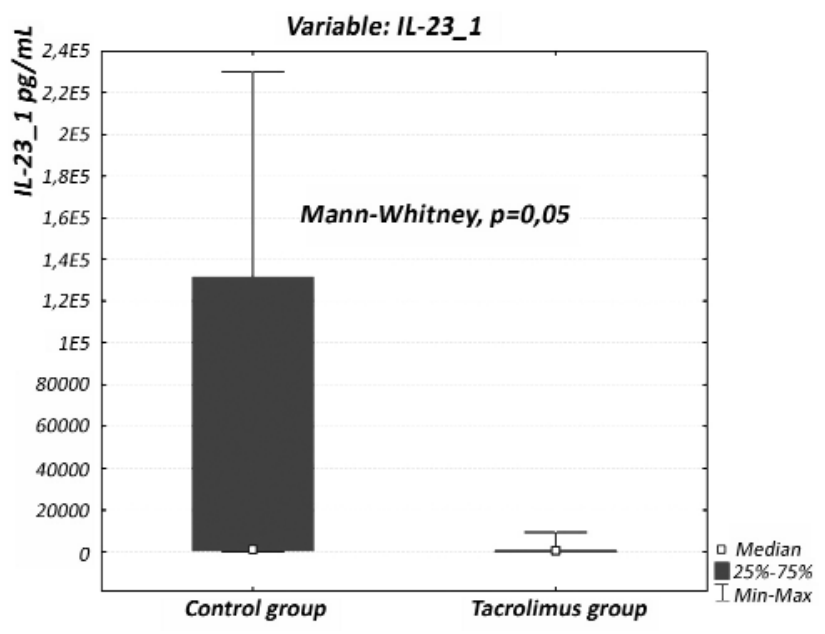

Figure 4 - Differences in IL-23 levels in the hepatic veins sample 1 hour after reperfusionbetween control and tacrolimus groups 
involvement of such factors as endothelin-1, Kupffer cells activation, reactive oxygen mediators accumulation, activation of adhesive molecules on the surface of endothelial cells of sinusoidal veins, sinusoidal veins spasm and thrombosis, ischemia, hepatic cells apoptosis and necrosis (5). Experimental studies of tacrolimus systemic use have demonstrated its efficacy with regard to IRI $(10,11,12)$. Several possible mechanisms of liver protection by tacrolimus use are known for IRI and LT. Among them is maintaining the glutathione level in hepatic cells according to the results of experimental works (12), inactivation of T-lymphocytes involved into sinusoidal endothelial cells damage of by means of adhesion and cytokines, chemokines and adhesive molecules release, interaction with Kupffer cells and platelets $(18,19)$, reduction of neutrophilic adhesion to endothelial cells of sinusoids and Kupffer cells inhibition $(20,13)$, reduction of vasoconstrictor substances expression, particularly, endothelin-1 (21), reduction of reactive oxygen mediators formation (22) and inhibition of TLR-4 gene transcription which is nowadays attributed the leading role in control of immune and inflammatory response in IRI (23).

Preliminary clinical studies of Peter S.D. and Kristo I. demonstrated possible benefit of flushing the liver before reperfusion with tacrolimus containing solution for reduction of AST and ALT levels and inhibition of anti-inflammatory cytokines transcription at the genomic level. Despite the promising data, the results of these studies could not be interpreted as reliable for introduction into clinical practice due to high probability of a random error. Study groups in both cases (10 and 13 patients) were insufficient for drawing clinical conclusions. Apart from design drawbacks, these studies had also methodic peculiarities not matching the liver protection idea of the method. Thus, in the work of Kristo I the pressure of $147 \mathrm{~mm} \mathrm{Hg}$ was used for portal vein perfusion, which can cause damage to endothelium of liver sinusoids and may lead to hepatic failure (24). Finally, in both studies donor organs suffered lower risk of IRI and subsequent EAD due to insignificant hepatic steatosis (1\%, Kristo I) and small median total ischemic time (384 min, Peter SD).

$20 \mathrm{ng} / \mathrm{mL}$ tacrolimus concentration in our study was chosen on the grounds of safety data in previous studies, as well as the range of maintained plasma concentrations recommended by manufacturer (25).

The difference of our method in convenient way of back-table flushing when the liver is cooled in the basin with ice; use of portal vein perfusion pressure $(40-60$ $\mathrm{cm}$ of gravity) excludes damage and activation of endothelial cells of sinusoids; hepatic artery flushing under the pressure of $40-50 \mathrm{~cm} \mathrm{Hg}$; presence of tacrolimus in the rinsing solution (albumin).

Portal and arterial perfusion of liver graft with the HTK solution and tacrolimus in our study resulted in reduced incidence of all EADs, particularly moderate-tosevere EAD according to the criteria of P.R. Salvalaggio ( $2.3 \%$ vs. $23.2 \%$ ), which was not demonstrated before.

The severity of hepatic cells necrosis in postreperfusion liver biopsy sample is a known sign of preservation and reperfusion injury and predictor of EAD (26). The morphological proof of this method's effect was reduced severe IRI incidence in postreperfusion live biopsy samples, which was not noted before in the studies of efficacy of pre-reperfusion flushing with tacrolimus.

Liver injury in the result of IRI is a typical example of damage-associated molecular patterns (DAMP) effect. DAMPs are their own tissues disintegration products possessing antigen-specific properties; they play the main role in induction of immune and inflammatory response at the early stage of organ failure, before the onset of infection. The modern model of DAMPmediated liver injury is presented below: necrotizing hepatic cells form several DAMP types, such as nuclear non-histone proteins (HMGB1), heat-shock proteins, mitochondrial DNA and cyclophilin A. Extracellular HMGB1 binds with several receptors, such as TLR2, TLR4, TLR9. Responding to TLR stimulation, macrophages and endothelial cells became activate. TLR-4 receptor-activated macrophages release IL-23. IL-23 stimulates $\gamma \delta$-T cells to produce IL-17. IL-17 recruits neutrophils into liver (27). It is also known that EAD incidence is associated with a certain profile of inflammatory cytokines in peripheral blood of both donors and recipients (28). In this regard, the results of this work are remarkable due to not only the change of IL-2, 6 levels 24 hours after reperfusion in peripheral blood of patients of the main group, but also IL-17 and IL-23 levels in liver outflow blood one hour after portal reperfusion, which explains the possible mechanism of action of portal and arterial perfusion with tacrolimus.

We didn't measure the dependence of IRI severity from tacrolimus concentration in effluent, that could be a significant additional research evidence.

The results in some part are the consequence of study circumstances - we don't accept marginal grafts in our Center (reflection of that is the average steatosis), median ischemia time only 8 hours and preservation solution - HTK. It is not excluded that use of marginal liver grafts, UW solution and different ischemia time could influence the study results.

The limitation of this study is an absence of the 
method's effect on hospital mortality.

Despite this, the study group of patients is a part of a cohort (307 patients at the time of writing this article) where patients with EAD suffered mortality risk 2.5 times higher than that in patients without $\operatorname{EAD}(p=0.012$; $95 \% \mathrm{Cl} 1.2-5.2$ ). On the other hand, hospital mortality in the cohort of 342 patients in our center amounts to $6.4 \%$, which does not allow assess the method's effect on mortality in the group of 43 patients from the statistical point of view. The economic effect of EAD prevention is important as well, as the cost of treatment of patients with EAD is known to exceed that of patients without EAD by several times.

Thus, use of HTK and albumin solutions with tacrolimus infusion into the portal vein and hepatic artery during the back-table is an effective method to reduce IRI, incidence and severity of EAD in grafts with medium preservation time and standard accepted steatosis level.

\section{REFERENCES}

1. Peralta C, Jiménez-Castro MB, Gracia-Sancho J. Hepatic ischemia and reperfusion injury: effects on the liver sinusoidal milieu. J Hepatol. 2013 Nov;59(5):1094-106.

2. Salvalaggio PR, Felga GE, Afonso RC, Ferraz-Neto BH. Early allograft dysfunction and liver transplant outcomes: a single center retrospective study. Transplant Proc. 2012 Oct;44(8):2449-51.

3. Pokorny H, Langer F, Herkner H, Schernberger R, Plöchl W, Soliman $T$, et al. Influence of cumulative number of marginal donor criteria on primary organ dysfunction in liver recipients. Clin Transplant. 2005 Aug;19(4):532-6.

4. Deschenes M. Early allograft dysfunction: causes, recognition, and management. Liver Transpl. 2013 Nov; 19 Suppl 2:S6-8.

5. Busuttil RW, Tanaka K. The utility of marginal donors in liver transplantation. Liver Transpl. 2003 Jul;9(7):651-63.

6. Kotsch K, Ulrich F, Reutzel-Selke A, Pascher A, Faber W, Warnick P, et al. Methylprednisolone therapy in deceased donors reduces inflammation in the donor liver and improves outcome after liver transplantation: a prospective randomized controlled trial. Ann Surg. 2008 Dec; 248(6):1042-50.

7. Minou AF, Shcherba AE, Dzyadzko AM, Rummo 00, Fedoruk AM, Slobodin YV, et al. Preconditioning with sevoflurane decreases the incidence of early allograft dysfunction in liver transplant recipients of steatotic grafts. Liver Transplantation. 2012;18 Suppl 1:S83.

8. Lang JD Jr, Teng X, Chumley P, Crawford JH, Isbell TS, Chacko BK et al. Inhaled NO accelerates restoration of liver function in adults following orthotopic liver transplantation. J Clin Invest. 2007 Sep; 117(9):2583-91.

9. Busuttil RW, Lipshutz GS, Kupiec-Weglinski JW, Ponthieux S, Gjertson DW, Cheadle C, et al. rPSGL-Ig for improvement of early liver allograft function: a double-blind, placebo-controlled, single-center phase II study. Am J Transplant. 2011 Apr;11(4):786-97.

10. Takeichi T, Uemoto S, Minamiguchi S, Takeyoshi I, Inomata Y, Tanaka $\mathrm{K}$, et al. Effect of ONO-4057 and tacrolimus on ischemia-reperfusion injury of the liver. World J Gastroenterol. 2009 Dec 7;15(45):5712-5.
11. Hüser N, Doll D, Altomonte J, Werner M, Kriner M, Preissel A, et al. Graft preconditioning with low-dose tacrolimus (FK506) and nitric oxide inhibitor aminoguanidine (AGH) reduces ischemia/reperfusion injury after liver transplantation in the rat. Arch Pharm Res. 2009 Feb; 32(2):215-20.

12. Pratschke S, Bilzer M, Grutzner U, Angele M, Tufman A, Jauch KW, et al. Tacrolimus preconditioning of rat liver allografts impacts glutathione homeostasis and early reperfusion injury. J Surg Res. 2012 Jul;176(1):309-16.

13. Kristo I, Wilflingseder J, Kainz A, Marschalek J, Wekerle T, Mühlbacher $F$, et al. Effect of intraportal infusion of tacrolimus on ischaemic reperfusion injury in orthotopic liver transplantation: a randomized controlled trial. Transpl Int. 2011 Sep;24(9):912-9.

14. Muehlschlegel JD. Muehlschlegel Closing the pore on reperfusion injury: myocardial protection with cyclosporine. Anesthesiology. 2014 Aug;121(2):212-3.

15. St Peter SD, Post DJ, Rodriguez-Davalos MI, Douglas DD, Moss AA, Mulligan DC. Tacrolimus as a liver flush solution to ameliorate the effects of ischemia/reperfusion injury following liver transplantation. Liver Transpl. 2003 Feb;9(2):144-9.

16. Hulley SB, Cummings SR, Browner WS, Grady DG, Newman TB. Designing Clinical Research. $4^{\text {th }}$ ed. Lippincott Williams \& Wilkins; 2013. p. 367 (Aviva Petrie \& Caroline Sabin. Medical statistics at a glance / Aviva Petrie. 3rd ed. Wiley-Blackwell; 2012.p. 180.

17. Olthoff KM, Kulik L, Samstein B, Kaminski M, Abecassis M, Emond J, et al. Validation of a current definition of early allograft dysfunction in liver transplant recipients and analysis of risk factors. Liver Transpl. 2010 Aug;16(8):943-9.

18. Khandoga $A$, Hanschen M, Kessler JS, Krombach F. CD4+ T cells contribute to postischemic liver injury in mice by interacting with sinusoidal endothelium and platelets. Hepatology. 2006 Feb;43(2):306-15.

19. Hanschen M, Zahler S, Krombach F, Khandoga A. Reciprocal activation between CD4+ T cells and Kupffer cells during hepatic ischemiareperfusion. Transplantation. 2008 Sep 15;86(5):710-8.

20. Squadrito F, Altavilla D, Squadrito G, Saitta A, Deodato B, Arlotta M, et al. Tacrolimus limits polymorphonuclear leucocyte accumulation and protects against myocardial ischaemia-reperfusion injury. J Mol Cell Cardiol. 2000 Mar;32(3):429-40

21. Soda Y, el-Assal ON, Yu L, Nagasue N. Suppressed endothelin-1 production by FK506 and cyclosporin A in ischemia/reperfusion of rat small intestine. Surgery. 1999 Jan;125(1):23-32.

22. Garcia-Criado FJ, Palma-Vargas JM, Valdunciel-Garcia JJ, Toledo AH, Misawa K, Gomez-Alonso A, et al. Tacrolimus (FK506) down-regulates free radical tissue levels, serum cytokines, and neutrophil infiltration after severe liver ischemia. Transplantation. 1997 Aug 27;64(4):594-8.

23. Howell J, Sawhney R, Testro A, Skinner N, Gow P, Angus P, et al. Cyclosporine and tacrolimus have inhibitory effects on toll-like receptor signaling after liver transplantation. Liver Transpl. 2013 Oct; 19(10):1099-107.

24. Garcea G, Maddern GJ. Liver failure after major hepatic resection. J Hepatobiliary Pancreat Surg. 2009;16(2):145-55.

25. https://www.astellas.us/docs/prograf.pdf

26. Koçbiyik A, Demirhan B, Sevmis S, Budakoglu I, Karakayali H, Haberal M. Role of postreperfusionsubcapsular wedge biopsies in predicting initially poor graft function after liver transplantation. Transplant Proc. 2009 Sep;41(7):2747-8.

27. Wang X, Sun R, Wei H, Tian Z. High-mobility group box 1 (HMGB1)-Tolllike receptor (TLR)4-interleukin (IL)-23-IL-17A axis in drug-induced damage-associated lethal hepatitis: Interaction of $y \delta \mathrm{T}$ cells with macrophages. Hepatology. 2013 Jan;57(1):373-84.

28. Friedman BH, Wolf JH, Wang L, Putt ME, Shaked A, Christie JD, et al. Serum cytokine profiles associated with early allograft dysfunction in patients undergoing liver transplantation. Liver Transpl. 2012 Feb; 18(2):166-76. 